\title{
Rupatadine to prevent local allergic reactions to sublingual allergy immunotherapy: a case series
}

Anne K. Ellis ${ }^{1^{*}}\left(\mathbb{0}\right.$, Lori Connors ${ }^{2 \dagger}$, Marie-Josee Francoeur ${ }^{3 \dagger}$ and Douglas P. Mack ${ }^{4,5+}$

\begin{abstract}
Background: Sublingual immunotherapy tablets (SLIT-T) are an effective treatment for allergic rhinitis (AR), but some patients experience local allergic reactions (LAR) in the first few weeks of treatment that can lead to treatment discontinuation. Although oral antihistamines are recommended for the treatment and pretreatment of LAR associated with SLIT-T, there are no clinical trial data to support this recommendation. Rupatadine is an H1 antihistamine that also inhibits platelet activating factor activity. The objective of this case series is to describe realworld clinical situations in which rupatadine was used to treat or mitigate SLIT-T-related LAR.
\end{abstract}

Case presentations: Five cases are presented by the managing allergist and off-label use of rupatadine is their expert opinion only. Patients in all 5 cases were treated with a SLIT-T (e.g. ragweed, tree, grass, or house dust mites) for the management of allergic rhinitis and experienced bothersome LAR with the first SLIT-T administration. In 3 cases, rupatadine $10 \mathrm{mg}$ was administered for the immediate treatment of LAR (either in-office with the first SLIT-T dose or for subsequent LAR experienced at home) and the symptoms resolved. In 3 cases, pretreatment with other secondgeneration $\mathrm{H} 1$ antihistamines was unable to prevent LAR and the patients discontinued the SLIT-T. In these 3 cases, switching to pretreatment with rupatadine allowed the patients to restart and tolerate SLIT-T treatment with minimal or no LAR. In these patients with an established history of LAR, proactive pretreatment with rupatadine in subsequent seasons or with initiation of a different SLIT-T mitigated the previously experienced LARs.

Conclusions: In the cases presented, treatment with rupatadine resolved LAR associated with SLIT-T treatment and rupatadine pretreatment appeared to mitigate subsequent LAR. Rupatadine may be an option to treat or improve the tolerability of the SLIT-T, potentially improving early treatment persistence.

Keywords: Allergic rhinitis, Angioedema, $\mathrm{H}-1$ antihistamine, Local allergic reactions, Platelet activating factor, Pruritus, Sublingual immunotherapy

\section{Background}

Allergy immunotherapy (AIT) is a recommended and effective treatment for allergic rhinitis (AR). AIT can be administered in the form of sublingual immunotherapy

\footnotetext{
*Correspondence: ellis.anne@kingstonhsc.ca

†Lori Connors, Marie-Josee Francoeur and Douglas P. Mack contributed equally to this work

${ }^{1}$ Division of Allergy \& Immunology, Department of Medicine, Queen's

University, 76 Stuart St, Kingston, ON K7L 2V7, Canada

Full list of author information is available at the end of the article
}

tablets (SLIT-T), the safety and tolerability of which have been demonstrated in multiple clinical trials [1-5] However, many patients experience mild to moderate local allergic reactions (LAR) to the SLIT-T; more than $80 \%$ of the adverse events related to SLIT-T treatment in clinical trials are LAR $[6,7]$. The most common LAR with SLIT-T are throat irritation, oral pruritus, ear pruritus, tongue pruritus, and mouth edema [6, 7]. Data from clinical trials indicate that the LAR associated with SLIT-T generally resolve within 30 to $60 \mathrm{~min}$ and cease 
after 2 weeks $[6,8]$. In most cases, the LAR do not require medical intervention, but for some patients the LAR may be uncomfortable and lead to SLIT-T discontinuation early in treatment $[6,9,10]$.

The LAR induced by SLIT-T are generally acute allergic reactions similar to skin prick test or pollen food syndrome reactions $[6,11]$. The allergen introduced into the oral mucosa elicits an IgE-mediated acute allergic response, in which histamine, platelet activating factor (PAF), and other mediators play a role (Fig. 1). Allergy expert panels suggest that $\mathrm{H} 1$ antihistamines can be used to treat or prevent LAR associated with SLIT-T [9, 10]. However, no second-generation $\mathrm{H} 1$ antihistamines are approved for this indication, and no clinical trials have formally evaluated the impact of antihistamines on SLIT-T LAR. Rupatadine is a second-generation
$\mathrm{H} 1$ antihistamine that is approved in Canada for the treatment of AR and chronic spontaneous urticaria in patients age 2 years and older [12]. Unlike other H1 antihistamines, rupatadine has potent anti-PAF activity through specific inhibition of the PAF receptor $[13,14]$. The objective of this case series is to describe real-world clinical situations in which rupatadine was used to treat or mitigate SLIT-T-related LAR.

\section{Case presentations}

The cases are presented by the managing allergist and off-label use of rupatadine is used at the discretion of the same. The consent form, protocol, and data collection sheet were reviewed for ethical compliance by the Queen's University Health Sciences and Affiliated

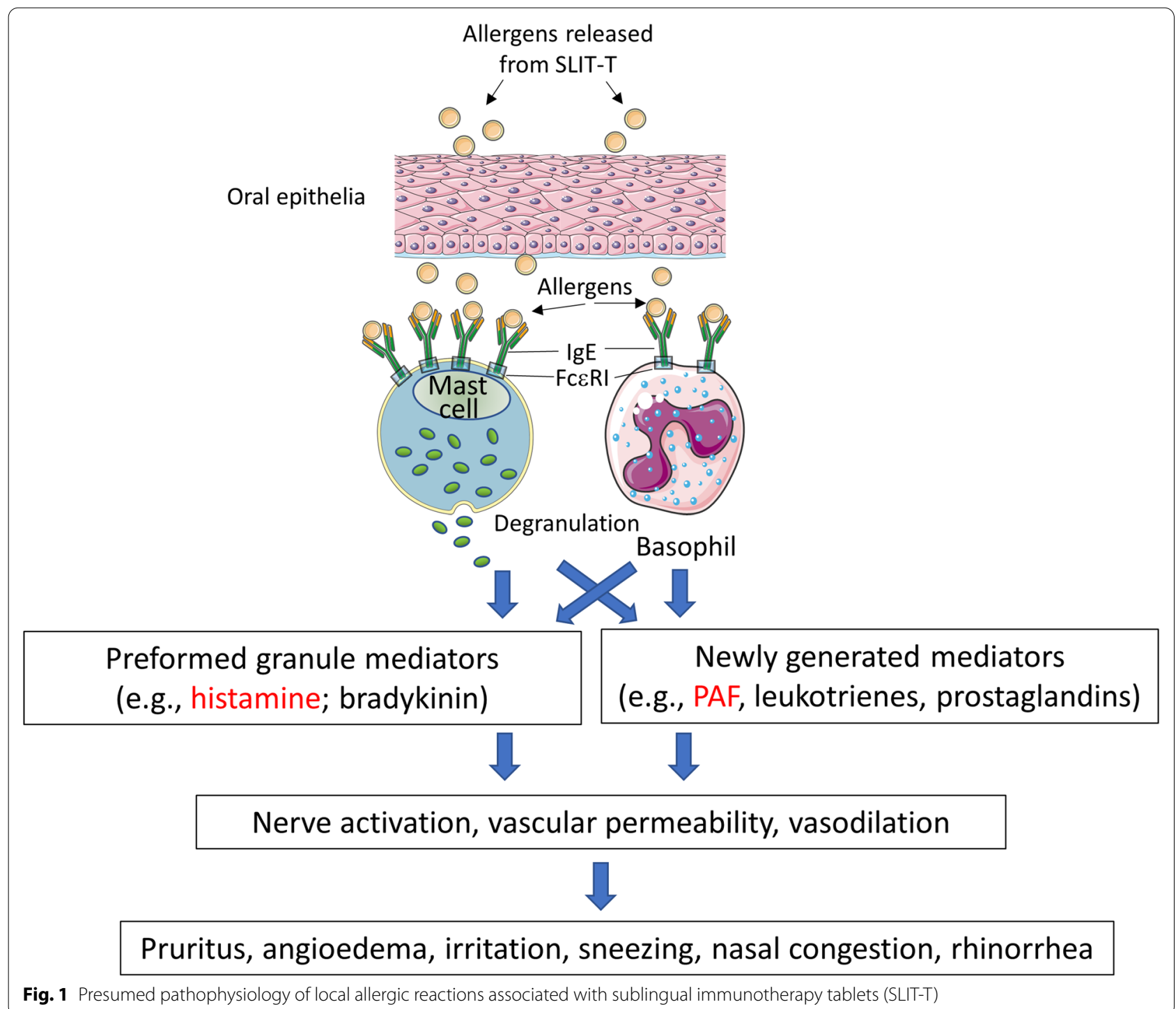


Teaching Hospitals Research Ethics Board and ethical clearance was granted.

Verbal and written consent was obtained from each case patient, when possible. When consent could not be obtained, the information in the case was presented in such a way as to anonymise the patient. Written consent for publication of the patient photograph was obtained from the patient's guardian.

\section{Case 1}

A 9-year old male presented with a history of AR during grass pollen season. The patient had concomitant controlled asthma treated with a daily low-dose inhaled corticosteroid (ICS). Skin prick test (SPT) indicated a sensitivity to grass (wheal $=9 \mathrm{~mm}$ ) and tree $\mathrm{mix}$ (wheal $=7 \mathrm{~mm}$ ).

A pre- and co-seasonal regimen of the 5-grass SLIT-T was prescribed. Beginning on day 1 during in-office administration, the patient experienced substantial, distressing daily mouth and throat symptoms that lasted up to $60 \mathrm{~min}$ after SLIT-T administration. Mild ear pruritus was also noted. Moderate lip angioedema occurred for the first 2 days of treatment, along with mild sublingual cavity angioedema. The patient was premedicated with $5 \mathrm{mg}$ oral cetirizine before subsequent SLIT-T administrations but discontinued the SLIT-T after 5 days because of the substantial daily mouth and throat symptoms. A sublingual sensation of possible mild swelling was noted for a few days after discontinuing the SLIT-T.

Treatment with the 5-grass SLIT-T was restarted one month after discontinuing initial treatment. Beginning on day 1 of the SLIT-T restart, pretreatment with rupatadine $5 \mathrm{mg}$ liquid solution was given $2 \mathrm{~h}$ before each SLIT-T dose. The patient experienced mild palate pruritus that lasted for less than 10 min on day 1 of the SLIT-T restart and mild ear pruritus that lasted for less than $10 \mathrm{~min}$ on day 3 . No angioedema or sublingual symptoms occurred. Pretreatment with rupatadine was given for the first 2 weeks of the SLIT-T restart and then was discontinued with no subsequent LAR associated with the SLIT-T. When the 5-grass SLIT-T was initiated for the next year's grass pollen season, the same rupatadine pretreatment regimen was proactively used for the first week of the SLIT-T administration. No LAR associated with the SLIT-T occurred. There were no adverse events associated with the rupatadine treatment.

\section{Case 2}

A 15-year old female presented with a history of AR during ragweed pollen season. SPT indicated a sensitivity to ragweed (wheal $=14 \mathrm{~mm}$ ), Dermatophagoides pteronyssinus (D. pteronyssinus; wheal $=8 \mathrm{~mm}$ ), and Dermatophagoides farinae (D. farinae; wheal $=6 \mathrm{~mm}$ ).

A pre- and co-seasonal regimen of the ragweed SLIT-T was prescribed. Over the first 7 days of SLIT-T administration, the patient experienced substantial and escalating mouth and throat symptoms. A globus sensation in the throat occurred on 3 of the first 7 days of SLIT-T treatment and a visible uvular swelling (observed in the office) occurred on 2 days. Sneezing was noted on 2 days. Daily pretreatment with desloratadine was begun on day 2 of SLIT-T treatment. However, on the 7th day of SLIT-T treatment a mild cough and throat symptoms developed and the patient discontinued the SLIT-T.

Treatment with the ragweed SLIT-T was restarted 6 weeks after discontinuing initial treatment. Beginning on day 1 of the SLIT-T restart, pretreatment with rupatadine $10 \mathrm{mg}$ tablet was given $2 \mathrm{~h}$ before each SLIT-T dose. The patient experienced mild mouth pruritus for the first 2 days of treatment. Pretreatment with rupatadine was given for the first 9 days of the SLIT-T restart and then was discontinued. The patient successfully completed the seasonal course of ragweed SLIT-T with no subsequent LAR and with a good symptom response. There were no adverse events associated with the rupatadine treatment.

\section{Case 3}

A 54-year old female presented with seasonal and perennial AR. Allergy history was assessed via telemedicine because of the COVID-19 pandemic. The patient had asthma triggered by cat exposure, which the patient avoided and therefore did not need asthma controller medication. Serum IgE results indicated sensitivity to birch, ragweed, grass mix, cat dander, dog dander, D. pteronyssinus, and D. farinae.

A pre- and co-seasonal regimen of the tree and timothy grass SLIT-T was prescribed, with plans for ragweed and house dust mite (HDM) SLIT-T to follow. Within 5 min of the first tree SLIT-T administration in the office, the patient experienced distressing mouth pruritus. Rupatadine $10 \mathrm{mg}$ tablet was administered immediately and the pruritus resolved within $25 \mathrm{~min}$. For subsequent home administration, the patient was instructed to take rupatadine $10 \mathrm{mg}$ every evening before bed for 2 weeks and to take the SLIT-T every morning. When the patient returned to the office 1-month later to initiate the timothy grass SLIT-T, she reported that the mouth pruritus associated with the tree SLIT-T had completely resolved with no recurrence during home administration. She had discontinued the rupatadine pretreatment. Proactive pretreatment with rupatadine $10 \mathrm{mg}$ tablet was given $1 \mathrm{~h}$ before the first timothy grass SLIT-T dose and the patient experienced no LAR. The patient continued to pretreat 
with rupatadine $10 \mathrm{mg}$ tablet for the first 2 weeks of the timothy grass SLIT-T as a precaution. There were no adverse events associated with the rupatadine treatment.

\section{Case 4}

A 17-year old male presented with a history of severe AR during the ragweed pollen season. The patient also had mild exercise-induced asthma which was treated with a short-acting beta-agonist as needed. SPT indicated sensitivity to ragweed (wheal $=12 \mathrm{~mm}$ ).

A pre- and co-seasonal regimen of the ragweed SLIT-T was prescribed. With the first dose of the ragweed SLIT-T in the office, the patient experienced intense tongue, mouth, and palate pruritus. Cetirizine $10 \mathrm{mg}$ liquid solution was administered immediately and the patient was kept under observation for $50 \mathrm{~min}$. The LARs resolved and the patient was sent home with instructions to administer cetirizine $10 \mathrm{mg} 1 \mathrm{~h}$ before daily at-home administration of the ragweed SLIT-T. After 1 week of ragweed SLIT-T treatment and cetirizine pretreatment, the patient was still experiencing mouth pruritus but was highly motivated to continue the ragweed SLIT-T treatment. Premedication was switched to rupatadine $10 \mathrm{mg}$ tablet and the ragweed SLIT-T was cut in half for 7 days. After finishing the 7 days of rupatadine pretreatment and half-dose of the ragweed SLIT-T, the patient reinitiated the full-dose SLIT-T with cetirizine pretreatment (rupatadine was not used because it was not reimbursed by the patient's insurance company; rupatadine was reimbursed during subsequent seasons). Within 3 days, the patient reported intense mouth pruritus and 2 large sublingual swellings (Fig. 2). Treatment with rupatadine $10 \mathrm{mg}$ liquid solution was administered and the sublingual swellings regressed after a few hours. The patient then discontinued SLIT-T treatment. Once the ragweed pollen season started, the patient was experiencing severe AR symptoms despite daily oral antihistamine and intranasal corticosteroid treatment.

The following May, pre-seasonal treatment with the ragweed SLIT-T was proactively initiated along with pretreatment with rupatadine $10 \mathrm{mg}$ tablet a few days before and $1 \mathrm{~h}$ before the first SLIT-T dose in the office. The patient experienced only mild mouth pruritus with the first dose of the SLIT-T. Pretreatment with rupatadine $10 \mathrm{mg}$ tablet $1 \mathrm{~h}$ before SLIT-T administration was maintained for the first 2 weeks, then the pretreatment rupatadine tablet dose was cut to $5 \mathrm{mg}$ for an additional 2 weeks before pretreatment was totally discontinued. There were no subsequent LAR associated with the SLIT-T and the patient successfully completed the seasonal course of ragweed SLIT-T. There were no adverse events associated with the rupatadine treatment.

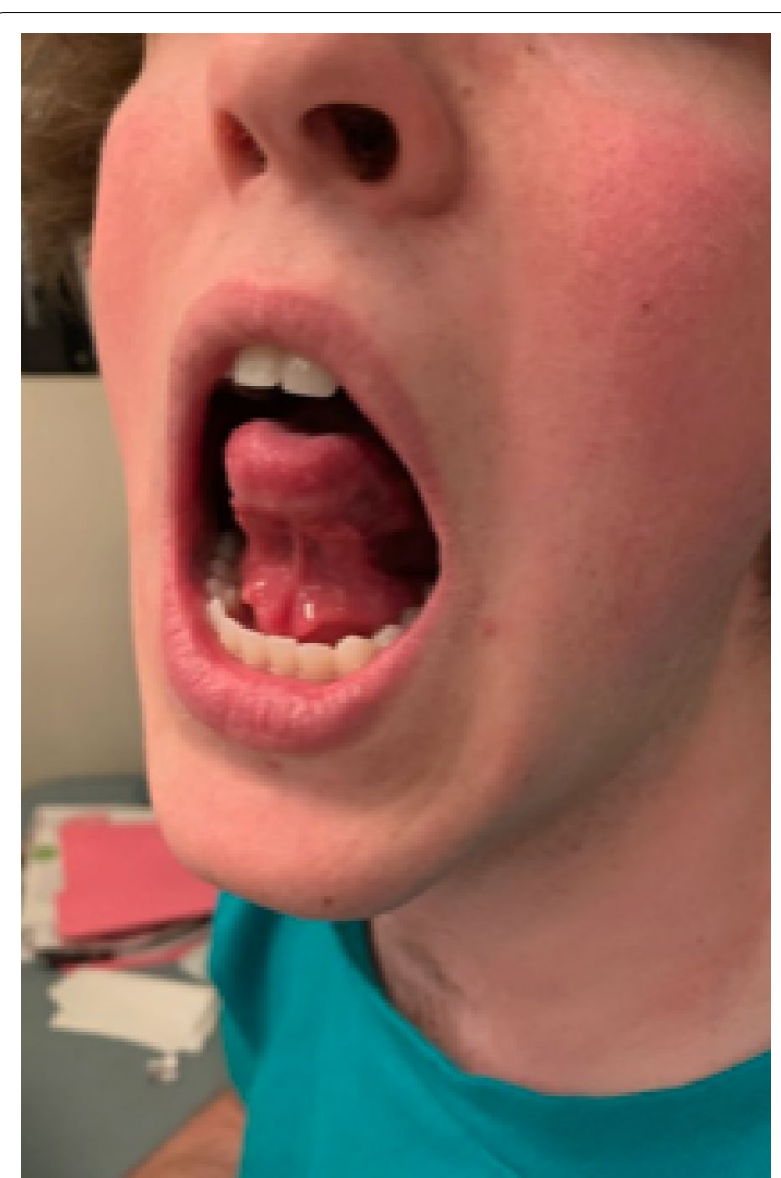

Fig. 2 Sublingual swellings associated with the ragweed SLIT-T

\section{Case 5}

A 28-year old male presented with perennial ARC. The patient had concomitant mild asthma well controlled by a combination ICS/long-acting beta-agonist. SPT indicated sensitivity to grass mix (wheal $=7 \mathrm{~mm}$ ) and HDM (wheal for $D$. farinae $=6 \mathrm{~mm}$ and for $D$. pteryonyssinus $=8 \mathrm{~mm}$ ).

A regimen of daily HDM SLIT-T and pre- and co-seasonal timothy grass SLIT-T was prescribed. The patient tolerated initiation with the timothy grass SLIT-T well, but with the first dose of the HDM SLIT-T in the office the patient experienced intense mouth pruritus and mild tongue angioedema. Rupatadine $10 \mathrm{mg}$ tablet was administered immediately and the LARs resolved within $40 \mathrm{~min}$. For subsequent home administration, the patient was instructed to take rupatadine $10 \mathrm{mg}$ tablet $30 \mathrm{~min}$ before SLIT-T administration for 8 weeks. After 8 weeks, the rupatadine pretreatment was reduced to every other day and then ultimately discontinued. The rupatadine pretreatment improved the tolerability of the HDM SLIT-T and the patient experienced only mild mouth pruritus with no angioedema. There were no adverse events associated with the rupatadine treatment. 


\section{Discussion and conclusions}

In the 5 cases presented, treatment with rupatadine resolved LAR associated with SLIT-T treatment and rupatadine pretreatment appeared to mitigate subsequent LAR. These cases are the first published reports focusing on the impact of an antihistamine for SLIT-related LAR treatment or pretreatment.

The ability to mitigate or prevent LAR is important for early persistence with SLIT-T treatment. In a study of 252 patients who initiated SLIT, $8 \%$ discontinued because of side effects in the first 10 days of treatment [2]. Before starting SLIT-T treatment, patients should be educated about the potential for LAR, what they may feel like, how long they will last, and if they will continue to reoccur [6]. LAR typically stop recurring after about 2 weeks, [6, 8 ] and pretreatment with antihistamines may enable the patient to better tolerate the LAR and continue treatment until then.

Proactive pretreatment with rupatadine was used in some of the presented cases to prevent LAR with SLIT-T restart in subsequent seasons or with initiation of a different SLIT-T. A history of LAR to SLIT-T was already established in these patients. An expert panel has recommended that the first administration of a SLIT-T should not be pretreated with antihistamine so that the patient's reaction to the SLIT-T can be properly assessed by the managing allergist [9].

Treatment of the LARs was sometimes with a liquid solution of antihistamine rather than a tablet. In our experience, the liquid solution is advantageous in relieving patient anxiety because the patient often believes the liquid works faster. Furthermore, the liquid solution coats the oral mucosa and may therefore induce a quicker response to the LAR than a tablet formulation, although this has not been scientifically evaluated. An analogous situation is allergic conjunctivitis where ophthalamic antihistamine formulations have an onset of action of about 15 min compared with $1-2 \mathrm{~h}$ for tablet antihistamine formulations [15].

In 3 of the cases, pretreatment with other secondgeneration $\mathrm{H} 1$ antihistamines was implemented to prevent LAR, but the LAR continued and were bothersome enough that the patients chose to discontinue the SLIT-T. In all 3 cases, the SLIT-T treatment was restarted with a rupatadine pretreatment and the LAR were minimal or absent compared with the previous SLIT-T treatment period. There are a couple of potential explanations as to why the LAR appeared to be reduced with rupatadine pretreatment but not the other antihistamines. First, rupatadine is the only H1 antihistamine that has anti-PAF effects through specific inhibition of the PAF receptor [13, 14]. Rupatadine may have inhibited PAF-induced LAR pathophysiologic processes in addition to those related to histamine, although a specific role for PAF in SLIT-T-associated LAR pathogenesis has not been elucidated. Indirect evidence for the role of PAF in SLIT-T-associated LARs is based on the known active role of PAF in hypersensitivity reactions and allergic inflammation, as well as the ability of anti-PAF agents to ameliorate these effects [16-18]. Secondly, there is a natural decrease in LAR over time with SLIT-T treatment as allergen tolerance develops. Therefore, the mitigation in LAR observed with rupatadine pretreatment could be attributed to the development of some level of tolerance from the first SLIT-T treatment period rather than a specific rupatadine effect. However, in some of the cases there was a substantial gap in taking the SLIT-T so tolerance may have been limited.

A limitation of these case observations is that while rupatadine treatment appeared to mitigate LAR in these particular patients, the results cannot be extrapolated to other patients and data from clinical trials are needed.

LAR associated with SLIT-T treatment can be uncomfortable for some patients and lead to treatment discontinuation. The presented cases demonstrate that rupatadine may be an option to treat or improve the tolerability of the SLIT-T, potentially improving early treatment persistence.

\section{Abbreviations}

AIT: Allergy immunotherapy; AR: Allergic rhinitis; HDM: House dust mite; ICS: Inhaled corticosteroid; LAR: Local allergic reactions; PAF: Platelet activating factor; SLIT: Sublingual immunotherapy.

\section{Acknowledgements}

Medical writing and editorial assistance were provided by Erin P. Scott, PhD, of Scott Medical Communications, LLC

\section{Authors' contributions}

The concept of the paper was conceived by the authors, led by AKE. All authors provided the information for the cases, interpreted the data, critically reviewed the manuscript, and approved the manuscript for submission. AKE obtained the Institutional Review Board waiver. All authors have read and approved the final manuscript.

\section{Funding}

Medical writing and editorial assistance provided by Erin P. Scott, of Scott Medical Communications, LLC, were funded by Medexus Pharmaceuticals Canada, Verdun, QC.

\section{Availability of data and materials \\ All data supporting the conclusions of this article are included within the article.}

\section{Declarations}

\section{Ethics approval and consent to participate}

The consent form, protocol, and data collection sheet were reviewed for ethical compliance by the Queen's University Health Sciences and Affiliated Teaching Hospitals Research Ethics Board. Ethical clearance to conduct this case series was granted (DMED-2465-21). 


\section{Consent for publication}

Verbal and written consent was obtained from each case patient, when possible. When consent could not be obtained, the information in the case was presented in such a way as to anonymise the patient. Written consent for publication of the patient photograph was obtained from the patient's guardian.

\section{Competing interests}

A.K. Ellis has participated in advisory boards for ALK-Abelló, AstraZeneca, Aralez, Bausch Health, Circassia Ltd, GlaxoSmithKline, LEO Pharma, Johnson \& Johnson, Merck, Mylan, Novartis, Pediapharm and Pfizer, has been a speaker for ALK, Aralez, AstraZeneca, Bausch Health, Boehringer-Ingelheim, CACME, Meda, Medexus, Mylan, Merck, Novartis, Pediapharm, Pfizer, The ACADEMY, and Takeda. Her institution has received research grants from AstraZeneca, Bayer, LLC, Circassia Ltd, Green Cross Pharmaceuticals, GlaxoSmithKline, Sun Pharma, Merck, Novartis, Pfizer, Regeneron and Sanofi. She has also served as an independent consultant to Allergy Therapeutics, Bayer, LLC, Ora Inc., and Regeneron in the past. L. Connors has been on advisory boards for Abbvie, ALK, Bausch Health, GlaxoSmithKline, and Sanofi. She has provided speaking engagements for AstraZeneca, GlaxoSmithKline, and Sanofi. M.J. Francoeur has served as a speaker and/or advisor for ALK, Bausch Health, Mylan, Pfizer, and Pediapharm. D. Mack has provided consultation and speaker services for Pfizer, Aimmune, Kaleo, Merck, Covis and Pediapharm, and has been part of an advisory board for Pfizer and Bausch Health. He sits on the editorial board for the Journal of Food Allergy and has served as an investigator for ALK-Abello.

\section{Author details}

'Division of Allergy \& Immunology, Department of Medicine, Queen's University, 76 Stuart St, Kingston, ON K7L 2V7, Canada. ${ }^{2}$ Department of Medicine, Dalhousie University, Halifax, NS, Canada. ${ }^{3}$ Division of Pediatric Allergy, University of Sherbrooke CISSS Montérégie Centre, Clinique des spécialistes Santé Dix 30, Elna Tiny Tots, Montréal, QC, Canada. ${ }^{4}$ Department of Medicine, McMaster University, Hamilton, ON, Canada. ${ }^{5}$ Halton Pediatric Allergy, Burlington, ON, Canada.

Received: 3 August 2021 Accepted: 18 November 2021

Published online: 04 December 2021

\section{References}

1. Biedermann T, Kuna P, Panzner P, et al. The SQ tree SLIT-tablet is highly effective and well tolerated: results from a randomized, double-blind, placebo-controlled phase III trial. J Allergy Clin Immunol. 2019;143:105866.e6.

2. Cox LS, Casale TB, Nayak AS, et al. Clinical efficacy of 300IR 5-grass pollen sublingual tablet in a US study: the importance of allergen-specific serum IgE. J Allergy Clin Immunol. 2012;130:1327-34.

3. Creticos PS, Maloney J, Bernstein DI, et al. Randomized controlled trial of a ragweed allergy immunotherapy tablet in North American and European adults. J Allergy Clin Immunol. 2013;131:1342-9 e6.
4. Nelson HS, Nolte H, Creticos P, Maloney J, Wu J, Bernstein DI. Efficacy and safety of timothy grass allergy immunotherapy tablet treatment in North American adults. J Allergy Clin Immunol. 2011;127:72-80 e2.

5. Nolte H, Bernstein DI, Nelson HS, et al. Efficacy of house dust mite SLIT-tablet in North American adolescents and adults in a randomized, placebo-controlled trial. J Allergy Clin Immunol. 2016;138:1631-8.

6. Bernstein DI, Bardelas JA Jr, Svanholm Fogh B, Kaur A, Li Z, Nolte H. A practical guide to the sublingual immunotherapy tablet adverse event profile: implications for clinical practice. Postgrad Med. 2017. https://doi. org/10.1080/00325481.2017.1302306.

7. Didier A, Bons B. Safety and tolerability of 5-grass pollen tablet sublingual immunotherapy: pooled analysis and clinical review. Expert Opin Drug Saf. 2015;14:777-88.

8. Li JT, Bernstein DI, Calderon MA, et al. Sublingual grass and ragweed immunotherapy: clinical considerations-a PRACTALL consensus report. J Allergy Clin Immunol. 2016;137:369-76.

9. Sturm GJ, Vogelberg C, Marchon M, et al. Coadministration of sublingual immunotherapy tablets and management of potential adverse effects: Austrian, German, and Swiss expert recommendations. Clin Ther. 2019:41:1880-8.

10. Calderon MA, Waserman S, Bernstein DI, et al. Clinical practice of allergen immunotherapy for allergic rhinoconjunctivitis and asthma: an expert panel report. J Allergy Clin Immunol Pract. 2020;8:2920-36.e1.

11. Scadding G, Durham S. Mechanisms of sublingual immunotherapy. J Asthma. 2009:46:322-34.

12. PrRUPALL ${ }^{\mathrm{TM}}$ (rupatadine fumarate). Full Prescribing Information. Verdun, QC.

13. Church MK, Máspero JF, Maurer M, Ryan D. The scope of pharmacological and clinical effects of modern antihistamines, with a special focus on rupatadine: proceedings from a satellite symposium held at the 21st World Allergy Congress, Buenos Aires, December 8, 2009. World Allergy Organ J. 2010;3:S1-s16.

14. Merlos M, Giral M, Balsa D, et al. Rupatadine, a new potent, orally active dual antagonist of histamine and platelet-activating factor (PAF). J Pharmacol Exp Ther. 1997;280:114-21.

15. Simons FE, Simons KJ. Histamine and $\mathrm{H} 1$-antihistamines: celebrating a century of progress. J Allergy Clin Immunol. 2011;128:1139-50.e4.

16. Casals-Stenzel J. Effects of WEB 2086, a novel antagonist of platelet activating factor, in active and passive anaphylaxis. Immunopharmacology. 1987;13:117-24.

17. Henriques MG, Weg VB, Martins MA, et al. Differential inhibition by two hetrazepine PAF antagonists of acute inflammation in the mouse. Br J Pharmacol. 1990;99:164-8.

18. Kajiwara N, Sasaki T, Bradding P, et al. Activation of human mast cells through the platelet-activating factor receptor. J Allergy Clin Immunol. 2010;125:1137-45.e6.

\section{Publisher's Note}

Springer Nature remains neutral with regard to jurisdictional claims in published maps and institutional affiliations.

\footnotetext{
Ready to submit your research? Choose BMC and benefit from:

- fast, convenient online submission

- thorough peer review by experienced researchers in your field

- rapid publication on acceptance

- support for research data, including large and complex data types

- gold Open Access which fosters wider collaboration and increased citations

- maximum visibility for your research: over $100 \mathrm{M}$ website views per year
}

At BMC, research is always in progress.

Learn more biomedcentral.com/submissions 